Editor's Note: These short reviews of recent JNeurosci articles, written exclusively by students or postdoctoral fellows, summarize the important findings of the paper and provide additional insight and commentary. If the authors of the highlighted article have written a response to the Journal Club, the response can be found by viewing the Journal Club at www.jneurosci.org. For more information on the format, review process, and purpose of Journal Club articles, please see http://jneurosci.org/content/ preparing-manuscript\#journalclub.

\title{
Is Spatial Context Privileged in the Neural Representation of Events?
}

\author{
(D) Halle R. Dimsdale-Zucker ${ }^{1 *}$ and $\odot$ Jonathan Nicholas ${ }^{2 *}$ \\ ${ }^{1}$ Center for Neuroscience and Department of Psychology, University of California, Davis, California 95618 and ${ }^{2}$ Department of Psychology, Columbia \\ University, New York, New York 10027 \\ Review of Robin et al.
}

\section{Introduction}

Spatial context has been central to theories of memory formation for decades, and it has been more recently suggested that an individual's spatial environment provides a base on which other components of a memory are built (Robin et al., 2016). Perhaps one reason for the initial focus on space was that many early experiments used rodents as research subjects, whose experiences are primarily defined by the spatial layout of mazes, boxes, and rooms. Space, therefore, became a common proxy for manipulating context and context-specific behaviors. But does spatial context actually have a privileged status?

Although the precise meaning of context is hotly debated, one working definition is that a context is the ongoing spatial, mental, emotional, temporal, or cognitive information that surrounds events (Robertson et al., 2015). For instance, your cur-

Received April 13, 2018; revised June 2, 2018; accepted June 6, 2018.

We thank Mariam Aly, Chris Baldassano, Zach Reagh, and Maureen Ritchey for comments and feedback on drafts of this manuscript.

*H.R.D.-Z. and J.N. contributed equally to this work.

The authors declare no competing financial interests.

Correspondence should be addressed to either of the following: Halle R. Dimsdale-Zucker Center for Neuroscience and Department of Psychology, University of California, Davis, California 95618, E-mail: hrzucker@ucdavis.edu; or Jonathan Nicholas Department of Psychology, Columbia University, New York, New York 10027, E-mail: jonathan.nicholas@columbia.edu.

DOI:10.1523/JNEUROSCI.0949-18.2018

Copyright $(\odot) 2018$ the authors $\quad 0270-6474 / 18 / 386241-03 \$ 15.00 / 0$ rent context includes the location where you are reading this paper, how alert you are right now, and the current time; in this way, space is merely one type of context. In support of this claim, both spatial and broader contextual processing have been shown to rely on overlapping medial temporal and posterior parietal regions (Aminoff et al., 2013; Miller et al., 2014). The computations performed by these regions may not be inherently spatial but could be co-opted to represent context more generally.

Recent work from Robin et al. (2018) examined the importance of spatial context in autobiographical memory. While in an MRI scanner, participants imagined novel combinations of familiar locations, people, and objects. The authors then used multivoxel pattern analysis to understand which regions represented the individual location, person, or object features of these imagined events, as well as the combined imagined events as a whole. Although there were regions whose activity patterns differentiated features within each of these categories, when the patterns associated with each category were directly compared, only location-specific regions demonstrated significantly higher classification performance. These regions overlapped with hubs of spatial processing in posterior parietal cortex like posterior cingulate cortex (PCC), retrosplenial cortex (RSC), and precuneus. Interest- ingly, the regions also overlapped with medial temporal [parahippocampal cortex (PHC)] and posterior cortical areas that have been linked to contextual processing (Buckner et al., 2008; Ranganath and Ritchey, 2012). Notably, the authors did not find evidence for location specificity in the hippocampus, despite strong prior evidence to suggest that the hippocampus represents spatial information and episodic contexts more generally (Dimsdale-Zucker et al., 2018).

\section{Spatial and nonspatial functions of medial temporal and posterior} parietal regions

Unsurprisingly, many of the regions Robin et al. (2018) reported as showing better classification for location than nonlocation information have been repeatedly linked to spatial processing. Much of this evidence comes from investigations of spatial impairments in humans and experimental animals with damage to these cortical areas. For example, disruptions to any of these regions along the parietomedial temporal pathway yield a general syndrome of navigational impairments commonly referred to as topological disorientation, and lesions to parietal sites result in spatial neglect syndrome (Boccia et al., 2018). Additionally, patients with damage to ventromedial posterior parietal cortex find it difficult to recall spatial routes (Takahashi et al., 1997), and the 
degree of PCC atrophy in Alzheimer's patients is correlated with their ability to construct fictitious scenes (Irish et al., 2015).

One challenge in interpreting the results of Robin et al. (2018) is that spatial processing is often confounded with episodic memory processes that extend beyond the spatial domain. These include imagination and self-perception (Buckner et al., 2008), binding contextual information (Aminoff et al., 2013), vividness (Richter et al., 2016), integration, and retrieval (Gilmore et al., 2015). Participants need not have relied solely on spatial cognition to imagine an autobiographical event in the present task but are likely to have recruited these non-spatial processes as well [but see Hassabis and Maguire (2007) for an argument that imagination is a type of scene construction]. Although similar paradigms have been shown to tap medial temporal and posterior parietal regions for spatial processing (Hassabis and Maguire, 2007), there is also evidence implicating these regions in nonspatial cognition more broadly.

To expand on the nonspatial functions of these regions, $\mathrm{PHC}$ activity is often related to the encoding and retrieval of memories lacking a spatial element, particularly in cases that require drawing associations between discrete items (Aminoff et al., 2013). Lesioning PHC in rats impairs the encoding of odor-odor associations (Alvarez et al., 2001), and PHC BOLD responses increase when encoding pairs of objects that were presented sequentially (Hales et al., 2009). RSC has also been linked to nonspatial functions, including representing stable behaviors and actions (Auger and Maguire, 2018) and binding together compound object associations (Robinson et al., 2011). Bilateral lesions to RSC can yield episodic memory impairments similar to those that occur in medial temporal lobe amnesia (Valenstein et al., 1987). In addition, RSC and ventral PCC are key nodes in the default mode network and are both involved in cognitive processes that necessitate internal focus (Buckner et al., 2008). Finally, precuneus, although spatially proximal to default mode regions, has instead been argued to be part of a frontoparietal memory control network (Gilmore et al., 2015). It supports vividness and mental imagery (Richter et al., 2016), processes that could be co-opted for either spatial or nonspatial functions. Together, these medial temporal and posterior parietal regions are implicated in a wide range of spatial and nonspatial processing, but spatial information does not need to be primary for these regions to support many of the episodic memory functions involved in imagining autobiographical events.

\section{When spatial context is really just context}

Given the unique ability of medial temporal and posterior parietal regions, and RSC/PCC in particular, to classify place elements of imagined events, Robin et al. (2018) made the argument that spatial context is primary in the neural representations of events. This perspective alone does not account for the seemingly disparate roles that these regions can play across multiple tasks and modalities. Furthermore, perhaps one reason why the authors identified only location-specific regions is that locations are often the largest feature of imagined events and are more likely to be recalled earlier and added spontaneously to event descriptions (Robin et al., 2016), effectively subsuming other aspects of the episode. This could mean that the classifier used by Robin et al. (2018) was not sensitive to information about location per se but was instead able to decode the fact that location is larger than both the person and object features.

A more parsimonious explanation for these results is that space is a context that, while particularly effective at encapsulating events, does not have any special priority over other types of contexts. Participants in the study by Robin et al. (2018) might have used space to define their imagined autobiographical events, but they could have used any other context-defining attribute given different instructions. Critically, we would predict that for a task in which another, nonspatial feature (e.g., time of day or mental state) preferentially defined context, a similar set of brain regions would show greater classification for the contextdefining feature. Rather than these regions performing separate spatial and nonspatial computations, they are driven by contextual information.

One example of a context-driven computation in posterior parietal cortex comes from evidence that these regions represent stability (Auger and Maguire, 2018) and play a general role in autobiographical memory (Buckner et al., 2008), both of which may aid in computing a metric of self-location even outside of the spatial domain. For instance, PCC represents self-location in a social hierarchy (Tavares et al., 2015) and is involved in updating evaluations of another person (Mende-Siedlecki et al., 2013). These stability and self-representation functions may, therefore, be recruited by a number of features depending on which defines context for a given task. Because the paradigm used by Robin et al. (2018) necessitates that participants imagine themselves within a spatial location, it is possible that the spatial information represented by PCC is indeed part of a metric of self-location. Although decoded here as space, asking participants to focus instead on simulating a conversation may have shifted preferential classification to the person feature.

A more general opinion is that spatial processing as well as social and objectbased processing all rely on processing complex associations and that this may, in fact, be the function for which these regions are specialized (Aminoff et al., 2013; Miller et al., 2014). In particular, tasks that require associative binding reliably activate medial temporal and posterior parietal regions across a variety of domains, including spatial (Bar and Aminoff, 2003), temporal (Turk-Browne et al., 2012), auditory (Robinson et al., 2011), olfactory (Alvarez et al., 2001), and multisensory (Robinson et al., 2011). Together, this evidence supports an alternative interpretation for the present findings: medial temporal and posterior parietal regions represent whatever feature provides the greatest opportunity for binding unique elements together, or, in other words, in representing contexts.

\section{References}

Alvarez P, Lipton PA, Melrose R, Eichenbaum H (2001) Differential effects of damage within the hippocampal region on memory for a natural, nonspatial odor-odor association. Learn Mem 8:79-86. CrossRef Medline

Aminoff EM, Kveraga K, Bar M (2013) The role of the parahippocampal cortex in cognition. Trends Cogn Sci 17:379-390. CrossRef Medline

Auger SD, Maguire EA (2018) Retrosplenial cortex indexes stability beyond the spatial domain. J Neurosci 38:1472-1481. CrossRef Medline

Bar M, Aminoff E (2003) Cortical analysis of visual context. Neuron 38:347-358. CrossRef Medline

Boccia M, Di Vita A, Palermo L, Committeri G, Piccardi L, Guariglia C (2018) The way to "left" Piazza del Popolo: damage to white matter tracts in representational neglect for places. Brain Imaging Behav. Advance online publication. Retrieved March 5, 2018. doi: 10.1007/s11682-018-9839-7.

Buckner RL, Andrews-Hanna JR, Schacter DL (2008) The brain's default network. Ann N Y Acad Sci 1124:1-38. CrossRef 
Dimsdale-Zucker HR, Ritchey M, Ekstrom AD, Yonelinas AP, Ranganath C (2018) CA1 and CA3 differentially support spontaneous retrieval of episodic contexts within human hippocampal subfields. Nat Commun 9:294. CrossRef Medline

Gilmore AW, Nelson SM, McDermott KB (2015) A parietal memory network revealed by multiple MRI methods. Trends Cogn Sci 19:534543. CrossRef Medline

Hales JB, Israel SL, Swann NC, Brewer JB (2009) Dissociation of frontal and medial temporal lobe activity in maintenance and binding of sequentially presented paired associates. J Cogn Neurosci 21:1244-1254. CrossRef Medline

Hassabis D, Maguire EA (2007) Deconstructing episodic memory with construction. Trends Cogn Sci 11:299-306. CrossRef Medline

Irish M, Halena S, Kamminga J, Tu S, Hornberger M, Hodges JR (2015) Scene construction impairments in Alzheimer's disease - a unique role for the posterior cingulate cortex. Cortex 73:10-23. CrossRef Medline

Mende-Siedlecki P, Cai Y, Todorov A (2013)
The neural dynamics of updating person impressions. Soc Cog Affect Neurosci 8:623631. CrossRef Medline

Miller AM, Vedder LC, Law LM, Smith DM (2014) Cues, context, and long-term memory: the role of the retrosplenial cortex in spatial cognition. Front Hum Neurosci 8:586. CrossRef Medline

Ranganath C, Ritchey M (2012) Two cortical systems for memory-guided behaviour. Nat Rev Neurosci 13:713-726. CrossRef Medline

Richter FR, Cooper RA, Bays PM, Simons JS (2016) Distinct neural mechanisms underlie the success, precision, and vividness of episodic memory. ELife 5:e18260. CrossRef Medline

Robertson BA, Eacott MJ, Easton A (2015) Putting memory in context: dissociating memories by distinguishing the nature of context. Behav Brain Res 285:99-104. CrossRef Medline

Robin J, Wynn J, Moscovitch M (2016) The spatial scaffold: the effects of spatial context on memory for events. J Exp Psychol Learn Mem Cogn 42:308-315. CrossRef Medline

Robin J, Buchsbaum BR, Moscovitch M (2018)
The primacy of spatial context in the neural representation of events. J Neurosci 38:27552765. CrossRef Medline

Robinson S, Keene CS, Iaccarino HF, Duan D, Bucci DJ (2011) Involvement of retrosplenial cortex in forming associations between multiple sensory stimuli. Behav Neurosci 125:578-587. CrossRef Medline

Takahashi N, Kawamura M, Shiota J, Kasahata N, Hirayama K (1997) Pure topographic disorientation due to right retrosplenial lesion. Neurology 49:464-469. CrossRef Medline

Tavares RM, Mendelsohn A, Grossman Y, Williams CH, Shapiro M, Trope Y, Schiller D (2015) A map for social navigation in the human brain. Neuron 87:231-243. CrossRef Medline

Turk-Browne NB, Simon MG, Sederberg PB (2012) Scene representations in parahippocampal cortex depend on temporal context. J Neurosci 32:7202-7207. CrossRef Medline

Valenstein E, Bowers D, Verfaellie M, Heilman KM, Day A, Watson RT (1987) Retrosplenial amnesia. Brain 110:1631-1646. Medline 